\title{
Corrigendum to "A Mass of Pancreatic and Gastric Heterotopia Causing a Small Bowel Obstruction in a 61-Year-Old Male”
}

\author{
Majd Alfreijat, ${ }^{1}$ Bassem Khalil, ${ }^{2}$ Jordan Jackobs, ${ }^{3}$ \\ William Anderson, ${ }^{4}$ and Jennifer Eschbacher ${ }^{4}$ \\ ${ }^{1}$ Department of Medicine, St. Joseph's Hospital and Medical Center, Phoenix, AZ, USA \\ ${ }^{2}$ Department of Medicine, Georgetown University, Washington, DC, USA \\ ${ }^{3}$ Department of Surgery, St. Joseph's Hospital and Medical Center, Phoenix, AZ, USA \\ ${ }^{4}$ Department of Pathology, St. Joseph's Hospital and Medical Center, Phoenix, AZ, USA \\ Correspondence should be addressed to Majd Alfreijat; majd_freijat@yahoo.com
}

Received 17 July 2017; Accepted 2 August 2017; Published 24 September 2017

Copyright (C) 2017 Majd Alfreijat et al. This is an open access article distributed under the Creative Commons Attribution License, which permits unrestricted use, distribution, and reproduction in any medium, provided the original work is properly cited.

In the article titled "A Mass of Pancreatic and Gastric Heterotopia Causing a Small Bowel Obstruction in a 61Year-Old Male" [1], the name of the first author was given incorrectly as Alfrejat. The author's name should have been written as Alfreijat. The revised authors' list is shown above.

\section{References}

[1] M. Alfrejat, B. Khalil, J. Jackobs, W. Anderson, and J. Eschbacher, "A Mass of pancreatic and gastric heterotopia causing a small bowel obstruction in a 61-year-old male," Case Reports in Gastrointestinal Medicine, vol. 2017, Article ID 3126108, 3 pages, 2017. 


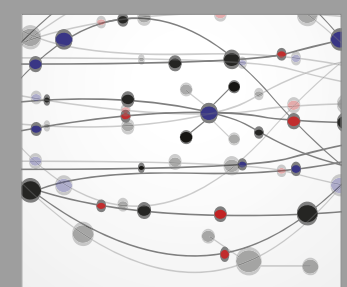

The Scientific World Journal
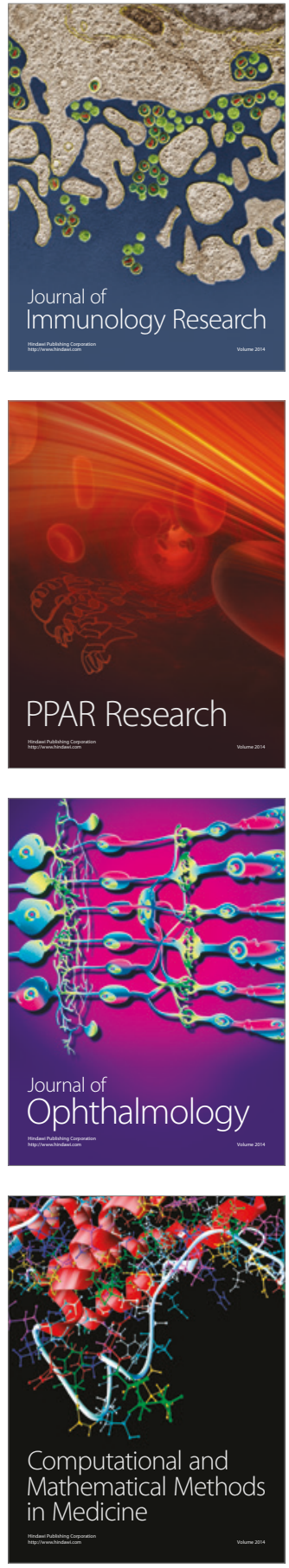

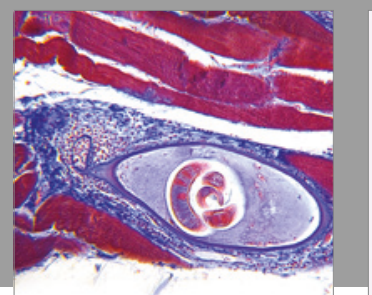

Gastroenterology Research and Practice
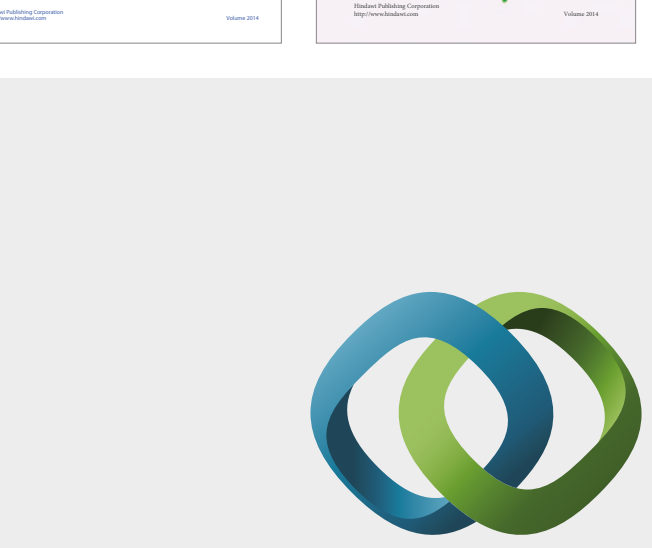

\section{Hindawi}

Submit your manuscripts at

https://www.hindawi.com
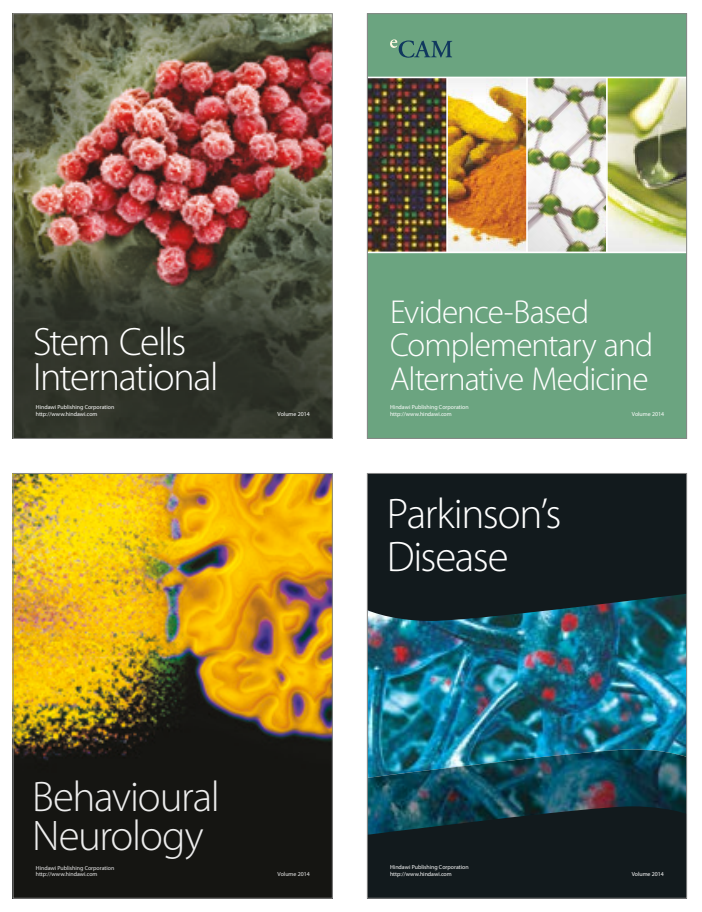
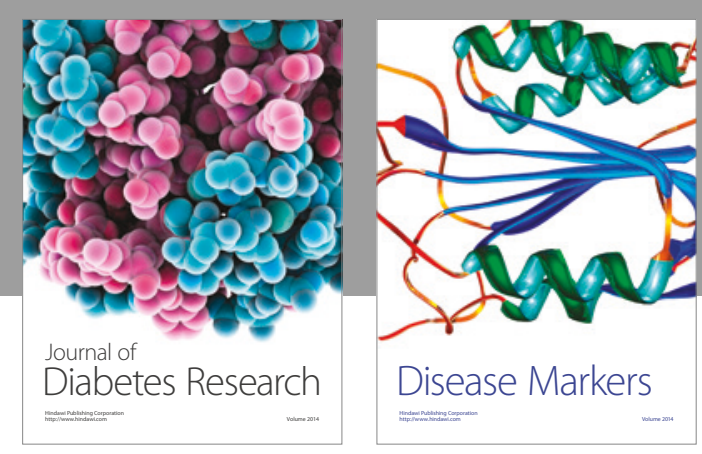

Disease Markers
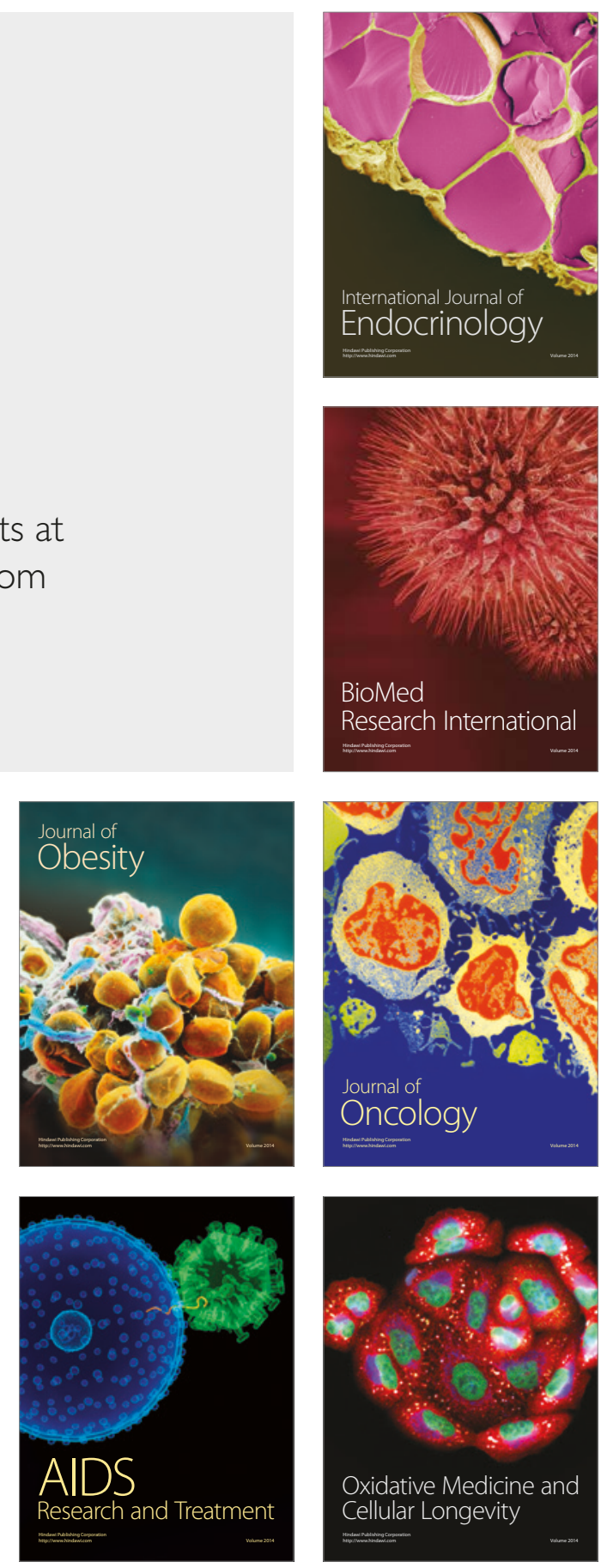